\title{
How does the mode of inheritance of a genetic condition influence families? A study of guilt, blame, stigma, and understanding of inheritance and reproductive risks in families with X-linked and autosomal recessive diseases
}

Cynthia A. James, ScM, PhD', Donald W. Hadley, $M S^{2}$, Neil A. Holtzman, MD, MPH ${ }^{3}$, and Jerry A. Winkelstein, $M D^{3}$

\begin{abstract}
Purpose: While the mode of inheritance of a genetic condition has long been considered to have not only medical, but also psychosocial consequences for families, this supposition has never been tested. Methods: We surveyed 112 members of 51 families (59\% response) with chronic granulomatous disease to determine the influence of mode of inheritance on parents', siblings', and patients' (1) knowledge of inheritance and reproductive risk; (2) concern about risk to future family-members; (3) feelings of guilt and blame; and (4) feelings of stigmatization. Ninety-six members of 51 families (49\% response) with Duchenne/Becker muscular dystrophy and spinal muscular atrophy types II/III were also studied. Results: X-linked families had better understanding of inheritance $(P<$ $0.001)$ and reproductive risks $(P<0.01)$. X-linked mothers worried more about risks to future generations; other autosomal-recessive family members were as worried. X-linked mothers were more likely to feel guilty $(P<0.01)$ and blame themselves $(P<0.001)$. X-linked fathers blamed their child's mother $(P<0.05)$ and X-linked mothers felt more blamed by the father $(P<0.01)$. X-linked family-members were more likely to consider being a carrier stigmatizing $(P<0.05)$. Conclusion: When providing genetic counseling, attention should be given to guilt and blame in X-linked families and understanding reproductive risks in autosomal recessive families. Genet Med 2006:
\end{abstract}

8(4):234-242.

Key Words: genetic counseling, chronic granulomatous disease, stigma, guilt, knowledge

The mode of inheritance of a genetic disease has long been proposed to have social and psychological consequences for affected families including the extent to which families worry about the health of future children, ${ }^{1}$ feel stigmatized, guilty, ${ }^{2}$ and blame the other parent, ${ }^{3}$ all of which affect a family's ability to adjust to the disease. ${ }^{2,4-6}$ For example, it has been suggested that X-linked inheritance facilitates the ascription of blame toward mothers more so than does a recessive disorder in which both parents contribute a deleterious gene. ${ }^{2,3}$ Mode of inheritance may also influence how well families learn about the inheritance of the condition. It has been suggested that extended families with multiple affected members (which are more likely in X-linked than autosomal recessive disease) may

\footnotetext{
From the ${ }^{I}$ Department of Medicine, Johns Hopkins School of Medicine, Johns Hopkins University; ${ }^{2}$ Social and Behavioral Research Branch, National Human Genome Research Institute, National Institutes of Health; ${ }^{3}$ Department of Pediatrics, Johns Hopkins School of Medicine, Johns Hopkins University.

Cynthia A. James ScM, PhD, Carnegie 592, Johns Hopkins Hospital, 600 North Wolfe Street, Baltimore, MD 21287-0409.

Submitted for publication December 19, 2005.

Accepted for publication February 7, 2006.
}

DOI: 10.1097/01.gim.0000215177.28010.6e be more knowledgeable about inheritance and reproductive risks. ${ }^{7}$ While these suppositions seem logical and clinically predicted, they remain untested.

Numerous studies have measured understanding of inheritance and reproductive risks, ${ }^{7-18}$ worry about reproductive risks, ${ }^{19-21}$ parental guilt and blame, ${ }^{22,23}$ and stigmatization, ${ }^{20,24,25}$ in both X-linked and autosomal diseases. However, as there has been little standardization of the questions used to measure these concepts in different populations, nor comparisons between autosomal and $\mathrm{X}$-linked recessive diseases, the influence of mode of inheritance has not been determined in a controlled fashion.

Accordingly, we developed a controlled study to assess the impact of X-linked (XL) and autosomal recessive (AR) inheritance on understanding of inheritance and personal reproductive risks, worry about recurrence of the condition, and feelings of guilt, blame, and stigmatization among family members of and patients with pairs of childhood-onset diseases. X-linked and autosomal recessive chronic granulomatous disease (CGD) provide a model for comparing the effect of mode of inheritance while controlling for differences in phenotype as the XL and AR forms of this primary immunodeficiency disorder are quite similar clinically. ${ }^{26}$ The other pairs of 
disorders used in this study, Duchenne Muscular Dystrophy (XL)/Spinal Muscular Atrophy type II (AR) and Becker Muscular Dystrophy (XL)/Spinal Muscular Atrophy type III (AR), are clinically distinct. However, their similarity in level of functional disability, clinical course, and the resulting modifications of family life provide sufficient similarities to use them to investigate of the influence of mode of inheritance across disease types.

\section{MATERIALS AND METHODS}

\section{Study design}

The study was a cross-sectional mail survey of adults with CGD (and their parents and siblings), Duchenne and Becker muscular dystrophy (MD), and spinal muscular atrophy (SMA) types II and III. Preliminary telephone interviews were conducted with ten families with CGD to aid in hypothesis generation and questionnaire design. ${ }^{27} \mathrm{All}$ study procedures were approved by the National Human Genome Research Institute's Institutional Review Board. Informed consent was obtained from each participant.

\section{Questionnaire design}

There were nine versions of the study questionnaire: parents', siblings' and affected adults' versions for CGD, MD, and SMA. The components of the parent, sibling, and affected adult questionnaires were similar but not identical. The wording of and response sets for questions that were not part of standardized scales, such as those about understanding inheritance and those measuring feelings of guilt and blame were derived from the preliminary interviews. ${ }^{27}$

\section{The questionnaires collected information on:}

Demographics (All questionnaires): Age, gender, education level

Family history (All): Who in the family was affected.

Understanding of mode of inheritance (All): Five original multiple choice questions measuring respondents' understanding of inheritance. These questions were developed so that they could be appropriately asked of familymembers with both $\mathrm{X}$-linked and autosomal recessive diseases.

Understanding of personal reproductive risks (All): Three original multiple choice questions asking respondents their chances of having an affected son, affected daughter, and carrier daughter.

Concerns about reproductive risk (All): Using a visual analog scale (VAS) all family-member were asked how worried they were about future generations of their family getting the disease in question, i.e., CGD, MD, or SMA. The VAS is a graphic measure used to quantify sensations. It is accepted as a good measure of physical and emotional pain..$^{28}$ The VAS is a line anchored by two extremes (such as extremely worried and not at all worried). Respondents are asked to mark the place on the line that best corresponds to how they feel.

Guilt and Blame (Parents): Six questions measured using a visual analog scale. The six-item guilt subscale of the short form of the Multiscore Depression Inventory (sMDI) ${ }^{29}$ was also used to measure guilt. This subscale has an internal reliability coefficient of $0.79 .^{30}$

Stigma (All): The Health Orientation Scale (HOS) ${ }^{31}$ was used to assess how respondents felt about their own or others' carrier status. The HOS consists of 12 five-point Likert scales developed to measure aspects of self-image and feelings toward carrier status. It was used initially to measure feelings about sickle cell trait ${ }^{31}$ and was later used by Evers-Kiebooms et al..$^{32}$ to assess the emotional impact of carrier testing for cystic fibrosis. A high internal reliability coefficient (0.97) was obtained when studying potential carriers of sickle cell disease. ${ }^{31}$

\section{Other Sources of Data}

Our recruitment sources, the Registry of U.S. Residents Affected by Chronic Granulomatous Disease and the investigators conducting CGD research at the National Institutes of Health, provided us with the mode of inheritance of CGD for each family. The local chapters of the Muscular Dystrophy Association (MDA) provided each participant's type of muscular dystrophy or spinal muscular atrophy.

\section{Recruitment}

Families affected by CGD were drawn from two sources: 1 ) 102 participants in National Institutes of Health intramural studies on CGD and 2) 369 enrollees (living and deceased) in the Registry of U.S. Residents Affected by Chronic Granulomatous Disease of the Immune Deficiency Foundation (CGD Registry). The CGD Registry permits contact of enrollees only through the physician who registered them. Therefore, we mailed these physicians letters requesting their help in inviting their patients to participate in our study by either obtaining permission from the families for us to contact them directly or forwarding letters of invitation we had enclosed. The letters of invitation were accompanied by a "Family Response Form" for families to return indicating their interest in participating and providing information allowing us to determine eligibility. Physician responses were tracked via a form they completed and mailed back to us. Participants or parents of participants in intramural NIH CGD research were directly mailed letters of invitation accompanied by a "Family Response Form."

Families affected with the neuromuscular conditions were invited to participate through their membership in the Maryland/Southern Delaware and Washington, DC chapters of the Muscular Dystrophy Association (MDA). Since membership in the MDA is based on the affected individual, only families with at least one living affected member were eligible for recruitment. Two hundred eighteen patients or parents of patients with Becker or Duchenne muscular dystrophy and 77 parents of or adults with SMA type II or III were directly mailed 
letters of invitation accompanied by a "Family Response Form" to return.

\section{Questionnaire administration}

"Family Response Form" respondents were contacted and the family history information they provided was verified. Respondents were asked which of their eligible family members might be interested in filling out a questionnaire. For each family member, the respondent chose whether they were sent a questionnaire to pass along or we sent the questionnaire directly to the relative. Two weeks after the questionnaires were mailed, a reminder letter was sent to non-respondents. Four weeks after the initial mailing, a second copy of the questionnaire was sent.

\section{Assignment of mode of inheritance}

Families recruited from the CGD Registry were assigned the mode of inheritance listed in the Registry. The Registry considers patients to have the X-linked form of CGD if either: 1) there is a positive family history of a maternal lateral male relative with the disease; 2) the mother of the patient has a positive carrier test showing two populations of neutrophils with respect to NBT reduction; 3) a mutation has been detected in the gene for gp $91^{\text {phox }}$; or 4) immunochemical analysis has revealed the absence of the protein $g p 91^{\text {phox }}$ or a decrease in the activity of cytochrome b (of which gp91 ${ }^{\text {phox }}$ is a component). Patients are considered to have an autososomal recessive mode of inheritance if either: 1) they are female; 2 ) they have a female relative with CGD; 3 ) a mutation has been detected in the gene for $\mathrm{p} 22^{\text {phox }}, \mathrm{p} 47^{\text {phox }}$, or p $67^{\text {phox }}$; or 4) immunochemical analysis has shown the absence of $\mathrm{p} 22^{\text {phox }}, \mathrm{p} 47^{\text {phox }}$, or $\mathrm{p} 67^{\text {phox }}$ proteins. ${ }^{26}$ Patients recruited from the NIH were assigned the mode of inheritance listed as part of their diagnosis in the NIH records which are similarly based on family history and immunochemical or molecular analysis.

\section{Statistical analysis}

For testing associations between two categorical variables, $\chi^{2}$ tests were used. To determine the association between a categorical variable and continuous dependent variables with normal distributions, either a two-tailed $t$ test (for a binary independent variable) or analysis of variance (for variables with more than two categories) was performed. If the continuous variable had either a skewed distribution or the sample was too small to determine the distribution, a rank-order method (Mann-Whitney) was used. Statistics were considered significant at the $P<0.05$ level.

Step-wise, logistic and linear regressions using forward selection were used to assess the independent effects of predictor variables on categorical and continuous outcome variables respectively. Any independent variable that was associated with an outcome variable at the $P<0.1$ level in bivariate analysis was entered into the regression model.

\section{RESULTS}

\section{Response rates}

Three-quarters (67/89) of CGD Registry physicians agreed to invite their patients to participate in the study. These physicians had registered a total 182 affected individuals. They forwarded our invitation to 120 patients/parents of patients (66\%), chose not to contact 23 (13\%), and had lost 39 (21\%) to follow-up. Physicians also invited an additional eight families not yet enrolled in the Registry to participate. Among the 128 parents or patients contacted, 52 (41\%) mailed back the family response form expressing interest in participating. These 52 responses comprised 48 families. The 102 affected individuals enrolled in NIH CGD research comprised 85 families. Of these families, 48 (57\%) mailed back a family response form expressing interest in participating, $2(2 \%)$ were not interested, $28(33 \%)$ did not return a form, and 7 (8\%) were lost to follow-up.

Of the 218 families with Becker or Duchenne muscular dystrophy who were mailed invitation letters, 68 (31\%) mailed back forms expressing interested in participating. Of the 77 families affected by spinal muscular atrophy, 22 (29\%) were interested in participating. It was not possible to determine how many neuromuscular families never received invitations because undeliverable mail went directly to the MDA main mail center.

Of the 96 CGD families who returned family response forms, 13 participated in an earlier interview phase of the study ${ }^{27}$ and were therefore not eligible to be sent questionnaires. Of the remaining 83 families, 69 (83\%) were called and agreed to be sent questionnaires. We were unable to contact nine $(11 \%)$ and five $(6 \%)$ were ineligible because an affected child was not a biological child. Questionnaires were mailed to 191 members of these 69 interested, eligible families.

Of the 89 neuromuscular families, $74(83 \%)$ were mailed questionnaires, nine (10\%) could not be contacted, three (3\%) declined to participate, one (1\%) respondent had died, and two $(2 \%)$ were ineligible because they had a different form of muscular dystrophy. Questionnaires were mailed to $196 \mathrm{mem}$ bers of the 73 interested, eligible families. One family withdrew from the study prior to returning study questionnaires because the affected individual died.

One hundred twelve (59\%) questionnaires were returned from members of 51 families (74\%) affected by CGD. Two CGD families provided information which put the mode of inheritance of their condition in question so they were dropped from the sample. Ninety-six questionnaires (49\%) were received from members of 51 families $(70 \%)$ with the neuromuscular conditions.

\section{Study population}

The final study population was composed of 110 individuals in 49 kindreds (37 XL, $12 \mathrm{AR}$ ) with CGD and 96 individuals in 51 neuromuscular kindreds (33 XL, $18 \mathrm{AR}$ ). The CGD sample was composed of 49 mothers, 20 fathers, 22 affected adults, 16 sisters, and five brothers. The neuromuscular sample included 40 mothers, 14 fathers, 18 affected adults, 16 sisters, and eight 
Table 1

Understanding inheritance and personal reproductive risk

\begin{tabular}{|c|c|c|c|c|}
\hline Question & Mode & $\begin{array}{c}\text { CGD } \\
\text { (\% correct) }\end{array}$ & $\begin{array}{l}\mathrm{MD} / \mathrm{SMA} \\
(\% \text { correct })\end{array}$ & $\begin{array}{c}\text { All } \\
\text { (\% correct) }\end{array}$ \\
\hline \multicolumn{5}{|l|}{ Understanding Mode of Inheritance } \\
\hline \multicolumn{5}{|l|}{ In families like mine: } \\
\hline $\begin{array}{l}\text { Only boys/men can be carriers } \\
\text { Only girls/women can be carriers } \\
\text { Both men and women can be carriers ( } 3 \text { choices) }\end{array}$ & $\begin{array}{l}\text { XL } \\
\text { AR }\end{array}$ & $\begin{array}{l}78 \\
79\end{array}$ & $\begin{array}{l}79 \\
72\end{array}$ & $\begin{array}{l}79 \\
75\end{array}$ \\
\hline $\begin{array}{l}\text { If a woman in your family is a carrier for CGD/MD/SMA, what is the chance that } \\
\text { her SON will have CGD/MD/SMA? (The father does not have CGD/MD/SMA } \\
\text { and is not a carrier) ( } 5 \text { choices) }\end{array}$ & $\begin{array}{l}\mathrm{XL} \\
\mathrm{AR}\end{array}$ & $\begin{array}{l}73 \\
58\end{array}$ & $\begin{array}{l}53 \\
49\end{array}$ & $\begin{array}{l}65 \\
53\end{array}$ \\
\hline $\begin{array}{l}\text { If a woman in your family is a carrier for CGD/MD/SMA what is the chance that } \\
\text { her DAUGHTER will also be a CARRIER? (The girl's father does not have } \\
\text { CGD/MD/SMA and is not a carrier) ( } 5 \text { choices) }\end{array}$ & $\begin{array}{l}\mathrm{XL} \\
\mathrm{AR}\end{array}$ & $\begin{array}{l}62^{c} \\
18\end{array}$ & $\begin{array}{l}49^{b} \\
19\end{array}$ & $\begin{array}{l}57^{c} \\
18\end{array}$ \\
\hline $\begin{array}{l}\text { What is the chance that the SON of a man in your family with CGD/MD/SMA } \\
\text { will also have CGD/MD/SMA? (The mother of the boy does not have } \\
\text { CGD/MD/SMA and is not a carrier) ( } 5 \text { choices) }\end{array}$ & $\begin{array}{l}\text { XL } \\
\text { AR }\end{array}$ & $\begin{array}{l}55 \\
55\end{array}$ & $\begin{array}{l}66^{b} \\
35\end{array}$ & $\begin{array}{l}59^{a} \\
43\end{array}$ \\
\hline $\begin{array}{l}\text { If a man with CGD/MD/SMA has a DAUGHTER, what are the chances she will } \\
\text { be a carrier? (The mother of the girl does not have CGD/MD/SMA and is } \\
\text { not a carrier) ( } 5 \text { choices) }\end{array}$ & $\begin{array}{l}\mathrm{XL} \\
\mathrm{AR}\end{array}$ & $\begin{array}{c}34^{b} \\
6\end{array}$ & $\begin{array}{r}19 \\
9\end{array}$ & $\begin{array}{c}28^{b} \\
8\end{array}$ \\
\hline \multicolumn{5}{|l|}{ Understanding Personal Reproductive Risk } \\
\hline $\begin{array}{l}\text { If you were to have a (another) SON what are the chances he would have } \\
\text { CGD/MD/SMA? ( } 5 \text { choices) }\end{array}$ & $\begin{array}{l}\mathrm{XL} \\
\mathrm{AR}\end{array}$ & $\begin{array}{l}73 \\
58\end{array}$ & $\begin{array}{l}62^{a} \\
42\end{array}$ & $\begin{array}{l}69^{b} \\
49\end{array}$ \\
\hline $\begin{array}{l}\text { If you were to have a (another) DAUGHTER what are the chances he would have } \\
\text { CGD/MD/SMA? ( } 5 \text { choices) }\end{array}$ & $\begin{array}{l}\mathrm{XL} \\
\mathrm{AR}\end{array}$ & $\begin{array}{l}66 \\
61\end{array}$ & $\begin{array}{l}64 \\
47\end{array}$ & $\begin{array}{l}65 \\
53\end{array}$ \\
\hline $\begin{array}{l}\text { If you were to have a (another) DAUGHTER what are the chances he would be a } \\
\text { CGD/MD/SMA carrier? ( } 5 \text { choices) }\end{array}$ & $\begin{array}{l}\mathrm{XL} \\
\mathrm{AR}\end{array}$ & $\begin{array}{l}65 \\
48\end{array}$ & $\begin{array}{l}55 \\
44\end{array}$ & $\begin{array}{l}61^{a} \\
46\end{array}$ \\
\hline
\end{tabular}

XL vs. AR: ${ }^{a} P<0.05,{ }^{b} P<0.01,{ }^{c} P<0.001$.

brothers. The sample was 91.2\% Caucasian/White, 6.3\% African American/Black, 1.5\% Hispanic/Latino, and 1\% Asian. Ninety-six percent of the respondents had a family-member living with the condition and $20 \%$ had lost an affected relative.

\section{Understanding of mode of inheritance and personal reproductive risks}

Table 1 shows respondents' understanding of inheritance and personal reproductive risks. XL respondents were significantly more likely to understand that an affected man and noncarrier woman were extremely unlikely to have an affected son $(P<0.05)$. XL respondents also had greater understanding of the $50 \%$ chance a carrier mother and $100 \%$ chance an affected father have of having a carrier daughter.

As illustrated in Figure 1, mothers, affected adults, and siblings in XL families all answered significantly more inheritance questions correctly than did their AR counterparts (the trend was similar for fathers but did not reach significance). There was no significant difference between the numbers of questions answered correctly by different family members (e.g., mothers, fathers, affected adults, siblings) in either the XL or AR groups. When entered into a linear regression model (Table 2), X-linked inheritance, higher level of education, and membership in a family with more than one affected member were independent predictors of knowledge of mode of inheritance. Position in the family (e.g., father, mother, etc.) and condition (CGD vs. neuromuscular) were not associated with knowledge of inheritance.

Members of XL families were also significantly more likely to understand their own reproductive risks (Table 1). With the exception of affected adults failing to understand their $100 \%$ chance of having a carrier daughter, the majority of XL mothers, fathers, affected adults and siblings understood their chance of having an affected son, affected daughter, and carrier daughter. In contrast, fewer than half of AR family members

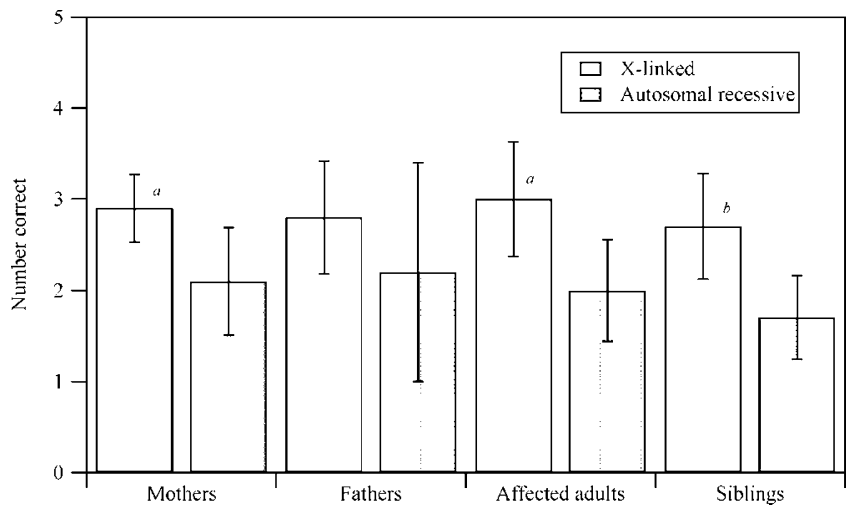

Fig. 1 Number of questions about inheritance answered correctly ( 0 to 5 ) by mode of inheritance. For comparisons of X-linked versus autosomal recessive: ${ }^{a} P<0.05 ;{ }^{b} P<0.01$. 
Table 2

Linear regressions: Understanding inheritance and understanding reproductive risks

\begin{tabular}{|c|c|c|c|}
\hline Variable & Coefficient (SE) $\beta$ & $95 \%$ CI for $\beta$ & Significance $(P<)$ \\
\hline \multicolumn{4}{|l|}{$\begin{array}{l}\text { Understanding mode of inheritance } \\
\text { (\# questions correct) }\end{array}$} \\
\hline Mode of inheritance $(\mathrm{AR}=0)$ & $0.75(0.20)$ & $0.37-1.14$ & 0.001 \\
\hline \multicolumn{4}{|l|}{ Type of family (index only $=0$ ) } \\
\hline $\begin{array}{l}>1 \text { sibling affected } \\
>1 \text { affected in separate nuclear } \\
\text { families (multiplex) }\end{array}$ & $\begin{array}{l}0.98(0.22) \\
0.64(0.28)\end{array}$ & $\begin{array}{l}0.55-1.41 \\
0.09-1.19\end{array}$ & $\begin{array}{l}0.001 \\
0.05\end{array}$ \\
\hline \multicolumn{4}{|l|}{ Education (high school $=0$ ) } \\
\hline $\begin{array}{l}\text { Some college } \\
\text { College grad } \\
\text { Some grad school }\end{array}$ & $\begin{array}{l}0.54(0.28) \\
0.58(0.31) \\
0.77(0.29)\end{array}$ & $\begin{array}{r}0.00-1.09 \\
-0.02-1.19 \\
0.19-1.35\end{array}$ & $\begin{array}{l}0.05 \\
0.1 \\
0.01\end{array}$ \\
\hline \multicolumn{4}{|l|}{$\begin{array}{l}\text { Understanding personal reproductive } \\
\text { risk (\# questions correct) }\end{array}$} \\
\hline Mode of inheritance $(\mathrm{AR}=0)$ & $0.45(0.19)$ & $0.15-0.75$ & 0.01 \\
\hline \multicolumn{4}{|l|}{ Education (high school = 0) } \\
\hline $\begin{array}{l}\text { Some college } \\
\text { College grad } \\
\text { Some grad school }\end{array}$ & $\begin{array}{l}0.68(0.21) \\
0.54(0.24) \\
0.76(0.23)\end{array}$ & $\begin{array}{l}0.25-1.10 \\
0.07-1.01 \\
0.31-1.21\end{array}$ & $\begin{array}{l}0.01 \\
0.05 \\
0.001\end{array}$ \\
\hline
\end{tabular}

knew their own chance of having an affected son or carrier daughter. When understanding of personal reproductive risk was considered as a four-point scale for number of questions answered correctly and variables were entered into a linear regression model, X-linked inheritance and higher level of education were independent predictors of understanding one's own reproductive risks (Table 2). Condition, position in the family, and number of affected members in the family were not significant predictors.

\section{Worry about future generations}

Using a 0-10 visual analog scale respondents were asked "How much have you worried about the possibility of future generations of your family getting CGD/MD/SMA?" As depicted in Table 3, both XL and AR family members were moderately worried. Mothers in XL families worried significantly more than mothers

Table 3

Worry about future generations

\begin{tabular}{lcc}
\hline Respondent & Mode & Mean (SE) \\
\hline Mother & XL & $6.4(0.34)^{a}$ \\
\multirow{3}{*}{ Father } & AR & $5.0(0.61)$ \\
& XL & $4.6(0.64)$ \\
Affected adult & AR & $6.2(0.48)$ \\
\multirow{2}{*}{ Sister } & XL & $4.1(0.59)$ \\
& AR & $5.3(0.79)$ \\
Brother & XL & $6.2(0.78)$ \\
& AR & $6.6(0.63)$ \\
& XL & $5.9(0.77)$ \\
\hline
\end{tabular}

XL vs AR: ${ }^{a} P<0.05 .0-10$ visual analog scale, $10=$ more worry. in AR families. However, there was no difference in the amount of worry experienced by sisters based on mode of inheritance. Bivariate analysis indicated that knowledge of reproductive risks and understanding of inheritance had no significant impact on level of worry in either XL or AR families.

\section{Guilt and blame}

As illustrated in Figure 2, XL mothers felt substantial guilt and self-blame, both currently and in the past, related to their child's condition. To test whether there were differences in feelings of guilt and self-blame by mode of inheritance and type of parent (mother vs. father), the Mann-Whitney test was used

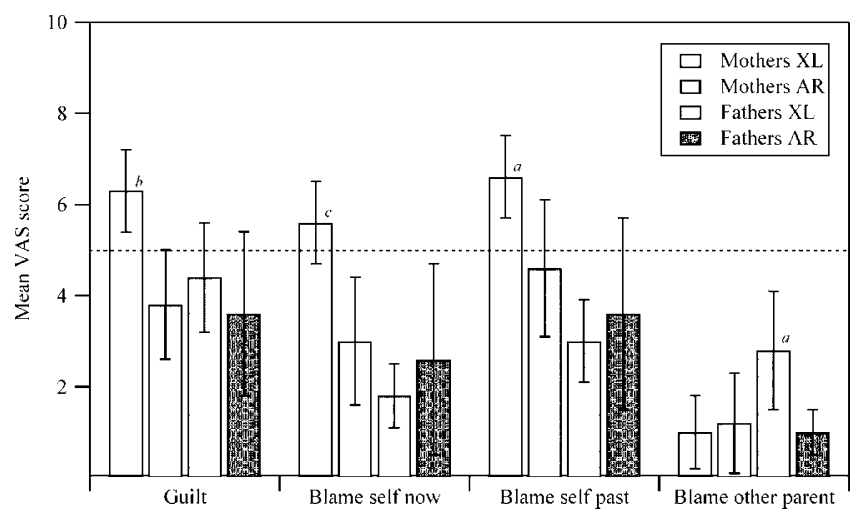

Fig. 2 Guilt and blame among parents. Using a $0-10$ visual analog scale (VAS), participants were asked: 1) How guilty do you feel about your child having (had) CGD/MD/ SMA? 2) Currently how much do you blame yourself for your child's CGD/MD/SMA? 3) In the past how much did you blame yourself for your child's CGD/MD/SMA? 4) How much did your blame your child's other biological parent for CGD/MD/SMA? The hashed line represents the midpoint of the VAS.

For comparisons of $\mathrm{X}$-linked mothers versus autosomal recessive mothers and $\mathrm{X}$-linked fathers versus autosomal recessive fathers: ${ }^{a} P<0.05 ;{ }^{b} P<0.01 ;{ }^{c} P<0.001$. 
because responses to the visual analog scale guilt and blame questions were not normally distributed. XL mothers felt significantly more guilty, were more likely to say they currently blamed themselves for their child's disease, and were more likely to admit to blaming themselves in the past than were AR mothers (Fig. 2). XL mothers also reported feeling more guilt $(P<0.05)$, current self-blame $(P<0.001)$, and past self-blame $(P<0.001)$ than did XL fathers. There were no differences in level of guilt or self-blame between AR mothers and fathers.

To confirm the influence of mode of inheritance on feelings of guilt in mothers, multivariate analysis was conducted. As responses to the guilt VAS score were not normally distributed, guilt scores were transformed into a categorical variable of less guilt (for VAS $<5$ ) or more guilt (VAS $\geq 5$ ) and logistic regression was performed. When entered into the model, XL inheritance and younger maternal age were significantly associated with more guilt (Table 4). Understanding of inheritance, disease (CGD/neuromuscular), education level, and family history (index case only, $>1$ case, siblings, $>1$ case, not siblings) were not associated with maternal guilt.

Guilt was also measured using the guilt subscale of the sMDI. XL mothers had significantly higher levels of guilt (mean 48.9, SE 1.2) than did AR mothers (mean 43.8, SE 2.0) $(P<0.05)$. Again, there was no difference in the scores of XL (mean 46.7, SE 2.2) and AR (mean 46.8, SE 3.1) fathers.

Although most parents did not report feeling substantial blame toward their child's other biological parent, XL fathers were significantly more likely to admit to blaming their child's mother than were AR fathers (Fig. 2). XL mothers were significantly more likely to admit to feeling more blamed by their child's father (mean 2.5, SE 0.39) than were AR mothers (mean 1.2, SE 0.41) $(P<0.01)$.

\section{Stigma}

Stigma associated with being a carrier was measured by the 12-60 point Health Orientation Scale (HOS). As illustrated in Figure 3, family members believe people feel moderate stigma when told they are a carrier. XL family members think this news creates somewhat greater stigma than do AR family members. In bivariate analysis, considering learning one is a carrier stigmatizing was significantly associated only with mode of inheritance; type of family member, disease, family history, and understanding of inheritance were not associated with HOS score.

Table 4

Logistic regression: Maternal guilt

\begin{tabular}{|c|c|c|c|}
\hline Variable & $\beta$ Coefficient (SE) & $95 \%$ CI for $\beta$ & Significance $(P<)$ \\
\hline $\begin{array}{l}\text { Mode of inheritance } \\
\quad(\mathrm{AR}=0)\end{array}$ & $1.28 \quad(0.55)$ & $1.22-10.43$ & 0.05 \\
\hline Age & $0.047(0.020)$ & $1.01-1.09$ & 0.05 \\
\hline
\end{tabular}

More guilt $=0$.

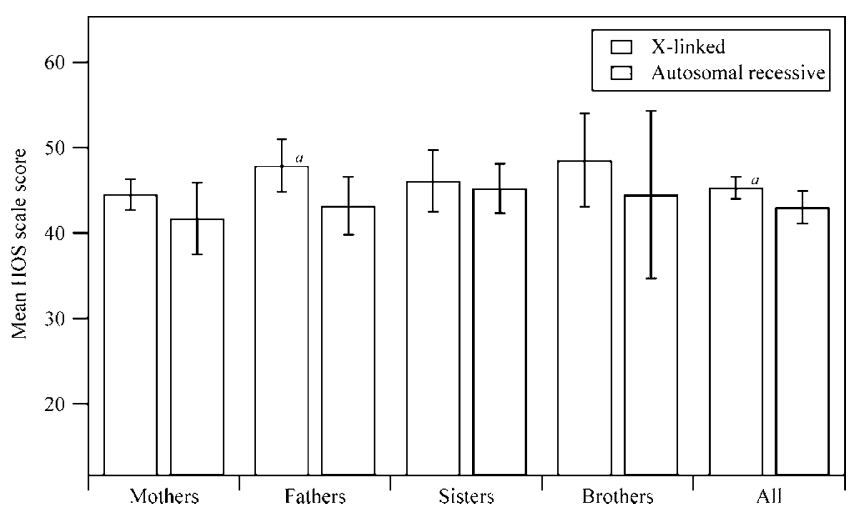

Fig. 3 Perception of stigma felt by carriers.

Participants were asked "How do you think most people feel when they are told they are MD/CGD/SMA carriers?” (12-item Health Orientation Scale (HOS) - range 12-60). For comparisons of X-linked versus autosomal recessive: ${ }^{a} \mathrm{P}<0.05$.

\section{DISCUSSION}

To our knowledge, this is the first controlled study to investigate the influence of mode of inheritance in families affected by X-linked and autosomal recessive conditions. The phenotypic similarity of XL and AR CGD allowed us to investigate the influence of mode of inheritance in a controlled manner. In addition, by studying different pairs of XL and AR diseases we were able to assess the generalizabilty of the influence of mode of inheritance. We found that, while members of XL families understood inheritance and their own reproductive risks better, most members of AR families were as worried about the risks to future generations as those in XL families. Conversely, those in XL families experienced considerably more guilt, blame, and sense of stigmatization related to the disease than did those in XL families.

Our findings are limited by several factors. Slightly less than half of CGD families and one-third of the neuromuscular families who were sent invitation letters were ultimately represented in the data analyzed. Participating families may have differed from non-participants in ways that skewed the results. For instance, families who believed that the disease had a powerful impact may have been more likely to participate, resulting in an overestimation of guilt, blame, and stigma. Fortunately, this bias is unlikely to alter the conclusions regarding the influence of mode of inheritance as it would likely affect XL and AR families in a similar manner. A second limitation is that multiple members of the same family completed questionnaires, compromising independence of study data. To control this issue, analyses were stratified by type of family member (mother, father, sister, etc.). Third, although our goal was to perform a controlled study of mode of inheritance, XL and AR CGD are not perfectly identical. Those with AR CGD have on average somewhat fewer CGD-associated complications. ${ }^{26} \mathrm{Fi}-$ nally, generalizability of findings may be limited to childhood/ young adult-onset conditions without significant cognitive impairment. 


\section{Understanding of inheritance and reproductive risks}

Our survey participants had a moderate understanding of inheritance, with XL families having a better understanding than AR families. XL respondents overestimated an affected man's chances of having an affected son and underestimated their chances of having a carrier daughter, findings similar to other studies. ${ }^{9}, 18,33$ Autosomal recessive family members overestimated the reproductive risks of affected individuals and siblings, deficiencies also reported elsewhere. ${ }^{12,22,34}$

These misunderstandings can have potentially harmful implications. In the case of siblings of individuals with cystic fibrosis, overestimates of reproductive risk led to longterm decisions to forgo marriage and childbearing. ${ }^{21}$ The failure of families to realize that all the daughters (XL) or children (AR) of an affected adult will be carriers can also have potentially devastating consequences, particularly in XL families where such girls may grow up unaware of the $25 \%$ chance they have of having an affected child with each pregnancy.

Several explanations of these deficiencies in families' understanding of inheritance and reproductive risks have been put forth. These include families ignoring the information because it was irrelevant in a time of crisis ${ }^{9}$ and avoiding the issue out of concern that their ill or disabled child will not experience sex or reproduction. ${ }^{35}$ Additionally, many adults with both XL and AR genetic conditions diagnosed during childhood continue to be followed by pediatric specialists who often do not discuss reproductive risk. ${ }^{36}$

While these explanations may account for some deficiencies in understanding inheritance and reproductive risk in our population, they do not explain the differences associated with mode of inheritance. Instead, the observed differences are likely the result of differences in perceived relevance of the information among both families and physicians. Although physicians' knowledge about genetics can be limited ${ }^{37}$ and pediatricians are often unaccustomed to discussing reproductive risk $^{36}$; it seems likely that due to the higher reproductive risks of women in XL families, health care workers may be especially motivated to ensure that XL families understand inheritance and their own reproductive risks. The information provided may eventually be better retained due to relevance to women and girls in the family. The guilt by XL mothers relating to their carrier status (as shown in the current study) may also encourage women to remember the basis of the inheritance of the disease, as information with strong emotional relevance is particularly likely to be retained.

\section{Worry about future generations}

Despite the empirically lower risk to future generations in AR families, fathers, siblings, and affected adults worry as much as their XL counterparts. This observation combined with our finding that understanding of reproductive risks had no significant impact on level of worry among all family members implies that, at least for fathers, siblings, and affected adults, worry is related less to empiric risks and understanding of those risks than to the experience of having an affected family member. This result is in line with studies showing that information alone is unlikely to alter feelings about reproductive risk. ${ }^{34,38}$

XL mothers worry more than their AR counterparts, possibly due to feelings of guilt associated with the mode of inheritance. We found XL mothers felt considerable guilt related to their child's condition. Anticipated guilt if grandchildren are affected may lead XL mothers to be particularly worried about the health of future family members.

\section{Guilt and blame}

Guilt and blame are common responses to a child's diagnosis. ${ }^{2}$ Parents make self- and other-based causal attributions for their child's illness as psychological defenses against powerful feelings of helplessness and meaninglessness resulting from receiving devastating news. ${ }^{4}$ Guilt implies control over the event and hence it's possible recurrence..$^{39}$ Blame, particularly maternal blame, is facilitated by men's tendency to externalize their emotional responses to devastating news and blame, while women are likely to internalize their responses and to accept this blame. ${ }^{40}$ This dynamic is furthered by the history of many previously poorly understood conditions (for instance autism, schizophrenia, immunodeficiency disorders) being attributed by health professionals to poor maternal care. ${ }^{35}$

Unresolved guilt can have serious implications. Guilt in parents of children with disabilities is associated with depression, helplessness, hopelessness, and disruption of effective parenting. ${ }^{39}$ As maternal guilt appears common in XL conditions, families affected by XL diseases may be at risk for such problems.

Poor outcomes for family function are also likely when a family member is blamed for a child's disability. ${ }^{41}$ Gender differences in placing and accepting blame ${ }^{40}$ tend to provide fathers with the opportunity to blame the mother and, therefore, to separate themselves from the shame of the ill or disabled child. This dynamic may lead to a separation between the father and an increasingly enmeshed mother-child bond. ${ }^{42}$ Based on our findings that XL fathers are the most likely to blame the other parent for the disease, the nature of X-linked inheritance facilitates this dynamic, putting at least the more vulnerable XL families at-risk for this destructive pattern.

\section{Stigmatization}

Members of XL families were somewhat more likely than AR family members to consider being a carrier as stigmatizing, in accordance with the greater implications carrier status has for reproductive risks in XL families. The level of stigmatization experienced was modest in both groups.

\section{CONCLUSIONS AND RECOMMENDATIONS}

This study has begun to address the question "How does the mode of inheritance of a genetic condition influence families?" Five disease characteristics have been identified that influence families ${ }^{43}$ : onset (acute or gradual); course (progressive or episodic); outcome (impact on lifespan); incapacitation; and pre- 
dictability. As the effects of mode of inheritance were the same for CGD (acute onset, episodic, periodically life-threatening, and unpredictable) and for the neuromuscular conditions (gradual onset, progressive, lifespan shortening, physically incapacitating, and relatively predictable), we believe the results of the study are likely generalizable to most other X-linked and autosomal recessive childhood/adolescent onset conditions. The following recommendations may improve clinical care for these families.

\section{Understanding inheritance and reproductive risks}

Despite their relatively low recurrence risk, medical visits with AR families should include genetic counseling regarding the reproductive risks of family members to address the worry associated with recurrence and hopefully avert life-altering choices based on misunderstandings of risk.

Families fail to understand the reproductive risks of affected men. As young men move through adolescence, medical visits should periodically include discussion of mode of transmission of the condition and reproductive risks.

In order for family-members to incorporate risk information they need an opportunity to discuss how new information about inheritance fits into previously held beliefs, This type of interactive discussion has been identified as a useful method for helping individuals internalize information about inheritance and reproductive risk. ${ }^{44}$

\section{Psychosocial consequences}

As maternal guilt and paternal blame are common, it is important that genetic counselors and other health professionals who often work with XL families begin developing psychoeducational strategies to address these issues in an ongoing fashion. In the interim, the following may be helpful.

Genetic counselors and physicians must be vigilant for signs of maternal guilt and paternal blame in XL families. Once detected, families should be provided the opportunity to discuss their feelings followed by brief interventions or a mental health referral as appropriate.

Maternal guilt and paternal blame may be prophylactically minimized if XL parents are provided anticipatory guidance shortly following the diagnosis. If families understand that feelings of guilt and blame are common and that the health care provider is accustomed to working with these issues, families may feel permitted to discuss feelings of guilt and blame, allowing the physician or genetic counselor to begin addressing these feelings early.

Participating in support groups either in person or online can help alleviate and normalize feelings of guilt. ${ }^{4,39,45} \mathrm{~A}$ referral to either a disease-specific organization or a general local support group for parents of children with chronic illnesses can be useful.

As persistent guilt can lead to depression, health care professionals should be alert to this possibility among XL mothers and provide a mental health referral if clinical depression is suspected.

\section{ACKNOWLEDGMENTS}

The authors thank the research team studying Chronic Granulomatous Disease in the intramural division of the $\mathrm{Na}$ tional Institute of Allergy and Infectious Diseases for inviting their patients to participate in the study and for providing technical information about CGD; the Immune Deficiency foundation for allowing us to use their Registry of U.S. Residents Affected by Chronic Granulomatous Disease; the Maryland/ Southern Delaware and Washington, DC chapters of the Muscular Dystrophy Association for helping us invite their members affected by MD and SMA to participate in the study; and the families who were so gracious in sharing their experiences.

This work was supported by the intramural branch of the National Human Genome Research Institute.

\section{References}

1. Weil J. Genetic counseling in the era of genomic medicine. EMBO Rep 2002;3:590593.

2. Kessler S, Kessler H, Ward P. Psychological aspects of genetic counseling III. Management of guilt and shame. Am J Med Genet 1984;17:673-697.

3. Weiss JO (1981). Psychosocial stress in genetic disorders: A guide for social workers. Soc Work Health Care 1981;6:17-31.

4. Weil J. Psychosocial Genetic Counseling. New York: Oxford University Press, Inc, 2000 .

5. Djurdjinovic L. Psychosocial counseling. In: Baker DL, Schuette JL, Uhlmann WR, editors. A Guide to Genetic Counseling. New York: Wiley-Liss, 1998;127-166.

6. Targum SD. Psychotherapeutic considerations in genetic counseling. Am J Med Genet 1981;8:281-289.

7. Eggers S, Pavanello RCM, Passos-Bueno MR, Zatz M. Genetic counseling for childless women at risk for Duchenne muscular dystrophy. Am J Med Genet 1999;86:447453.

8. De Braekeleer M, Rault G, Bellis G. Reproductive attitudes of couples having a child with cystic fibrosis in Brittany (France). J Hum Genet 2004;49:285-289.

9. Fanos JH, Davis J, Puck JM. Sib understanding of genetics and attitudes toward carrier testing for X-linked severe combined immunodeficiency. Am J Med Genet 2001;98:46-56.

10. Pajari H, Koskimies O, Muhonen T, Kaariainen H. The burden of genetic disease and attitudes toward gene testing in Alport syndrome. Pediatr Nephrol 1999;13:471476

11. Denayer L, Welkenhuysen M, Evers-Kiebooms G, Cassiman J-J, et al. Risk perception after CF carrier testing and impact of the test result on reproductive decision making. Am J Med Genet 1997;69:422-428.

12. Conway SP, Pond MN, Hamnett T. Knowledge of adult patients with cystic fibrosis about their illness. Thorax 1996;51:34-38.

13. Sawyer SM, Phelan PD, Bowes G. Reproductive health in young women with cystic fibrosis: knowledge, behavior and attitudes. J Adoles Health 1995;16:46-50.

14. Ranta S, Lehesjoki A, Peippo M, Kaariainen H. Hemophilia A: Experiences and attitudes of mothers, sisters, and daughters. Pediatr Hematol Oncol 1994;11:387397.

15. Denayer L, De Boeck K, Evers-Kiebooms G, Van den Berghe H. The transfer of information about genetic transmission to brothers and sisters of parents with a CF child. Birth Defects Orig Artic Ser 1992;28:149-158.

16. Costakos D, Abramson RK, Edwards JG, Rizzo WB, et al. Attitudes toward presymp tomatic testing and prenatal diagnosis for adrenoleukodystrophy among affected families. Am J Med Genet 1991;41:295-300.

17. Henley LD, Hill ID. Global and specific disease-related information needs of cystic fibrosis patients and their families. Pediatrics 1990;85:1015-1021.

18. Varekamp L, Suurmeijer TBBM, Brocker-Vriends AHJT, van Dijck H, et al. Carrier testing and prenatal diagnosis for hemophilia: Experiences and attitudes of 549 potential and obligate carriers. J Med Genet 1990;37:147-154.

19. Marteau TM, Anionwu E (1996). Evaluating carrier testing: Objectives and out comes. In: Marteau TM, Richards MPM, Editors. The Troubled Helix: Social and Psychological Implications of the New Hum Genet Cambridge, United Kingdom: Cambridge University Press, 1996:123-139.

20. Denayer L, Welkenhuysen M, Evers-Kiebooms G, Cassiman J-J, et al. The CF carrier status is not associated with a diminished self-concept or increased anxiety: Results of psychometric testing after at least 1 year. Clin Genet 1996;49:232-236.

21. Fanos JH, Johnson JP. Barriers to carrier testing for adult cystic fibrosis sibs: The importance of not knowing. Am J Med Genet 1995;59:85-91. 
22. Fanos JH, Mackintosh M. Never again joy without sorrow: The effect on parents of a child with ataxia-telangiectasia. Am J Med Genet 1999;87:413-419.

23. McConkie-Rosell A, Spiridigliozzi GA, Iafolla T, Tarleton J, et al. Carrier testing in the Fragile X syndrome: Attitudes and opinions of obligate carriers. Am J Med Genet 1997;68:62-69.

24. Karetti M, Yardumian A, Karetti D, Modell B. Informing carriers of beta-thalassemia: giving the good news. Genet Test 2004;8:109-113.

25. Fanos JH, Johnson JP. Perception of carrier status by cystic fibrosis siblings. Am J Hum Genet 1995;57:431-438.

26. Winkelstein JA, Marino MC, Johnston RB Jr, Boyle J, et al. Chronic granulomatous disease: Report on a national registry of 368 patients. Medicine 2000;79:155-169.

27. James CA, Holtzman NA, Hadley DW. Perceptions of reproductive risk and carrier testing among adolescent sisters and parents of males with chronic granulomatous disease. Am J Med Genet C Semin Med Genet 2003;119:60-69.

28. Carlsson AM. Assessment of chronic pain I. Aspects of the reliability and validity of the visual analog scale. Pain 1983;16:87-101.

29. Berndt DJ, Berndt SM, Kaiser CF. Multidimensional assessment of depression. J Pers Assess 1984;48:489-494.

30. Berndt DJ, Berndt SM, Kaiser CF. Evaluation of a short form of the Multiscore Depression Inventory. J Consult Clin Psychol 1983;51:790-791.

31. Woolridge EQ, Murray RF. The Health Orientation Scale: a measure of feelings about sickle cell trait. Soc Biol 1989;35:123-136.

32. Evers-Kiebooms G, Denayer L, Welkenhuysen M, Cassiman J-J, et al. A stigmatizing effect of the carrier status for cystic fibrosis? Clin Genet 1994;46:336-343.

33. Sorensen SA, Hasholt L. Attitudes of persons at risk for Fabry's disease towards predictive tests and genetic counselling. J Biosoc. Sci 1983;15:89-94.

34. Fanos JH, Gatti RA. A mark on the arm: Myths of carrier status in siblings of individuals with ataxia-telangiectasia. Am J Med Genet 1999;86:338-346.
35. Marshak LE, Seligman M, Prezant F. Disability and the family life cycle: Recognizing and treating developmental challenges. New York: Basic Books, 1999.

36. Hull S. Sickle cell disease, cystic fibrosis, and reproduction: a qualitative study of affected adult and health care provider perspectives [dissertation]. Baltimore, MD: Johns Hopkins University, 1999.

37. Doksum T, Bernhardt BA, Holtzman NA. Carrier screening for cystic fibrosis among Maryland obstetricians before and after the 1997 NIH consensus conference. Genet Test 2001;5:111-116.

38. Parsons EP, Clarke AJ. Genetic risk: Women's understanding of carrier risks in Duchenne muscular dystrophy. J Med Genet 1993;30:562-566.

39. Nixon CD, Singer GHS. Group cognitive-behavioral treatment for excessive parental self-blame and guilt. A J Ment Retard 1993;97:665-672.

40. Lewis M. Shame and stigma. In: Gilbert P, Andrews B, editors. Shame: interpersonal behavior, psychopathology, and culture. New York: Oxford University Press, 1998: 126-140.

41. Garwick AW. Variations in families' explanation of childhood chronic conditions: a cross-cultural perspective [dissertation]. Minneapolis, MN: University of Minnesota Hospital, 1997.

42. Frey KS, Greenberg MT, Fewell RR. Stress and coping among children: a multidimensional approach. Am J Ment Retard 1989;94:240-249.

43. Rolland JS. Families, illness, and disability: An integrative treatment model. New York: Basic Books, 1994.

44. Smith ACM. Patient education. In: Baker DL, Schuette JL, Uhlmann WR, editors. A guide to genetic counseling. New York: Wiley-Liss, 1998:99-121.

45. Nixon CD. Reducing self-blame and guild in parents of children with severe disabilities. In: Singer GHS, Powers LE, editors. Families, disability, and empowerment: Active coping skills and strategies for family interventions. Baltimore, MD: Paul H. Brookes Publishing Co., 1993:175-201. 